\title{
12 What Is English in the Light of Lingua Franca Usage?
}

\author{
Iris Schaller-Schwaner and Andy Kirkpatrick
}

\section{Introduction}

The origin of the term 'Lingua Franca' is unclear. According to Ostler (2010, p. 7), Lingua Franca "seems to be a retranslation of some Eastern-Mediterranean term for "language of the Franks"'. Ostler also notes (2010, p. 4) the "original 'Lingua Franca' was once a particular language ... the common contact language of the EasternMediterranean in the first half of the second millennium, the pidgin Italian in which Greeks and Turks could talk to Frenchmen and Italians". He defines a Lingua Franca as a "contact language used for communication among people who do not share a mother tongue" (2010, p. 36). Seidlhofer points out that the term has Latin roots meaning something like 'free language'. "It is thus not fanciful to think of 'Lingua Franca' as 'free language' ... a means of intercultural communication not particular to countries and ethnicities, a linguistic resource that is not contained in, or constrained by traditional (and notoriously tendentious) ideas of what constitutes a 'language"" (2011, p. 81).

That a Lingua Franca is circumscribed as a linguistic resource not constrained by traditional views of language and as a contact language raises the question of what a contact language is and, indeed, what a language is. The idea of language or a language is considered in depth by Hall (this volume). We suggest that a contact language can be seen as the outcome of social and individual bi- and multi-lingualism so that the use of one shows traces of the other. At the same time, one must be aware that this thinking is steeped in the monolingual mindset that assumes 'normal' languages to be pure. In the context of English as a Lingua Franca (henceforth ELF), this means that ELF can be linguistically influenced by contact with the other languages of the speakers who use ELF. As there is no limit to speakers who use ELF, this, in turn, means that, theoretically in any event, ELF can be 
linguistically influenced by any of the languages in any ELF speaker's linguistic repertoire. ELF is thus subject to unbounded variation. It is therefore not a stable easily definable 'thing'. ELF, as a form, is "inherently, chronically, irremediably variable" and "is also inherently hybrid in nature" (Firth, 2009, p. 163). This also leads us to note that the very definition of what a language is becomes slippery, or "notoriously tendentious" as noted. The variation in ELF and its causes - incorporating both the contact between the linguistic resources in the speaker's own head and mouth and contact with speakers of other 'languages' - give us an insight into language itself.

From a multi-lingual point of view, we would argue that English isn't just English and ELF isn't just English only. It is a way of being and doing English with other 'languages' in (the back of one's) mind and in a specific setting. ELF is a multi-lingual practice with a largely monolingual surface and with attributes that derive from the multilingual work that is going on when English is chosen as a mode of communication used with intentionality or ostentation: as an overt behaviour enhancing salience/drawing attention to itself and thus contributing to content meaning (Scott-Phillips, 2012, 2017), from the mutual permeability of 'languages' in the language users' repertoires, and from the multi-lingual nature of the encounter or speech event in the context in which it is embedded. Following Bell's (2001) reworking of audience design and what can motivate language choice, ELF can be a 'responsive' choice that caters to its own and interlocutor's or audience's perceived fit of linguistic repertoires and their incongruent first languages. Yet, ELF can also be an 'initiative' choice motivated by needs, desires, and purposes beyond the sheer negotiation of transactional meaning, a choice that changes and re/ co-constitutes the local context into which it is embedded. Even in cases where its use does not emerge as agentively, ELF is essentially always a choice in that a selection has to be made, a decision has to be executed, linguistic resources have to be activated for output and others inhibited.

English is not just one language but a label encompassing many different varieties of a 'plurilithic' entity (Hall, 2013). English, one may argue historically, is itself a contact language influenced over several centuries by many different languages from Germanic, Norman French, classical Greek, and Latin to languages spoken across the world today. Historically, English has also been a multi-lingual enterprise in that code mixing was common (see for example, the chapters by Fischer, Schendl, and Wright in Schreier and Hundt, 2013). 
This is not to deny that languages can be described as the thousands of grammar books that are available testify. However, these grammar books describe an idealised form of the language - what, in Hall's taxonomy (this volume) would be classified as an N-LANGUAGE - and would imply that speakers constantly use the forms as presented in the grammar books. Even comprehensive descriptive grammars only capture some of the variation inherent in language. However, by appearing in a grammar book, particularly a certain type of prescriptive grammar, a linguistic form is apparently given approval and legitimised as the 'standard' form, thereby rendering other forms as inferior in some way.

So, we are faced with a conundrum. On the one hand, it seems that language is a system, something that is relatively stable and that can be described and compared. This view sees language as an object. Traditional ontologies of language tend to be essentialist; that is to say that they treat language as a thing (Ortega, 2018). On the other hand, language is seen as a form of social practice (e.g. Saraceni, 2015), where language is a process characterised by perpetual change and regulated by contextual factors. We agree that language is a social practice and constantly changing, but we also recognise that it is regarded by its adult, literate users as something that can indeed be described and taught. As Joseph has noted, "so long as people believe that their way of speaking constitutes language in its own right, there is a real sense in which it is a real language" (2006, p. 27). Following Heller (2007), one will also have to bear in mind that 'language' and 'identity' are not natural phenomena but social constructs and that "the messiness of actual usage" (2007, p. 13) cannot be understood if one does not take this into account.

A language, then, is not easy to categorise. On the one hand it is a system; on the other it is a dynamic shifting phenomenon subject to variation along variables ranging from social settings, genres, register$s$, and influence from other languages to the idiosyncratic uses of an individual. Indeed, familiarity with the linguistic resources and idiosyncrasies of one's interlocutors is a significant aid to mutual understanding in ELF communication. ELF, then, is not a stable 'thing' but rather a description of how English is used by people who share this resource.

A recent definition of Lingua Franca by Seidlhofer is "any use of English among speakers of different first languages for whom English is the communicative medium of choice" (2011, p. 7). This, we feel, captures the essence of a Lingua Franca. Two points can be highlighted here. The first is that, as noted, a Lingua Franca can be 
regarded as a contact language, as an outcome of bi- and multilingualism, and it is important to note that a Lingua Franca is a multi-lingual endeavour. Bi- and multi-linguals develop, expand, and refine the resources in their linguistic repertoire in order to communicate with other multi-linguals. Multi-linguals also have to call on their linguistic resources in the moment that they need to language, while assessing which of their linguistics resources can be or need to be called upon to affect successful communication with their interlocutor(s). The Lingua Franca will be open to influence from the first languages of the speakers who have adopted the language as a Lingua Franca. This first language influence is most obviously noted in the different pronunciations that different speakers will have. But first (and other) language influences can be seen at the levels of grammar and discourse, and in phenomenon such as code-switching. It is useful to consider and perhaps qualify the current overgeneralisation that ELF researchers are only now discovering multi-lingualism. While a pedigree in English (applied) linguistics or English language teaching (ELT) may predispose one to see the shape of English before the ground of multi-lingualism when looking at ELF rather than the other way round, there has been awareness and consideration of the multilingual features of ELF and of ELF as a multi-lingual phenomenon, explicitly for example in Klimpfinger (2005, 2007, 2009), Smit (2005), Kirkpatrick (2010a, b), Schaller-Schwaner (2011), Cogo (2012), or Hülmbauer and Seidlhofer (2013).

Starting with Grosjean's (e.g. 2001) functional holistic account of how bi- and multi-linguals can travel along a continuum of language modes between monolingual and bilingual ends and synthesizing this approach with compatible multi-lingualism constructs, SchallerSchwaner (2017, pp. 15-49) has identified cornerstones of multilingualism that can be drawn together as five contingencies "that together lead on to their conceptual relevance for English as a lingua franca". These are (2017, p. 59):

1. assuming that individual bi- and multi-lingualism is not an accumulation of monolingualisms and that multi-lingual repertoires and multi-competence are variable, dynamic, and asymmetrical with interacting linguistic resources that are shaped by use

2. given that additional language users may choose their additional language not only to talk to its L1 speakers but to other additional language users

3. provided that we still want to identify, count, describe, or explain (resources from) the languages that wax and wane in people's different modes of functioning in multi-lingual situations 
4. further, in order to explore how languages and languaging (language as a practice) are functioning outside traditional L1 speech communities or stable bilingual communities as well as

5 . in order to interrogate traditional notions of ideal communicators (and language teachers), it is highly desirable if not compelling to conceive of individual languages not only in terms of L1 or native language varieties but also in terms of plurilingual uses. One would thus go beyond multi-lingualism with English (Hoffmann, 2000) and turn the perspective into English with multi-lingualism, or English as a Lingua Franca.

These points summarise what we take to be the basic tenets of ELF. Having established ELF as inherently dynamic, multi-lingual, and subject to inherent variation, we want, in this chapter, to investigate how a language is adopted as a Lingua Franca in different settings. First we describe how English came to be the Lingua Franca of the Association of Southeast Asian Nations (ASEAN). Then we refer to research conducted by Schaller-Schwaner $(2011,2015,2017)$ where she describes how English was adopted as a Lingua Franca at the University of Fribourg, Switzerland. The University of Fribourg is Switzerland's only bilingual university (German and French are the two official languages) and, as we shall show, the use of English as an academic language was officially discouraged. This provides an example of ELF use in a relatively bounded setting compared with the wide range of settings in which ELF occurs in ASEAN.

\section{English as a Lingua Franca in ASEAN}

ASEAN was first established in Bangkok in 1967. There were five founding member states, namely, Thailand, the Philippines, Malaysia, Singapore, and Indonesia. The founding document, the Bangkok Declaration, made no mention of language and which language(s) might be official languages of the group. Instead, delegates involved in setting up ASEAN indicated that they simply assumed English would be the working language. Delegates were quoted as saying: "the idea of English as the common language came out automatically', 'there has been no regulation for the use of English but it has been used in all the actual situations', and 'we took it for granted"' (Okudaira, 1999, pp. 95-96).

That the delegates simply assumed English would be the common language of ASEAN is extremely surprising given that two of the founding member states, Indonesia and Thailand, had no history of English. In contrast, the Philippines, Malaysia, and Singapore had all 
been colonies of English-speaking nations and were countries where English played an institutional role and had developed their own varieties of English (Kirkpatrick, 2007, 2010a). The acceptance of English as the working language clearly discriminated against Thailand and Indonesia as they had few proficient speakers of English compared with the other three nations. One might have expected Malay/Indonesian to be named the working language, as it was an official or national language of three of the founding member states, Indonesia, Malaysia, and Singapore, and spoken to some extent in both the Philippines and Thailand. When one of the authors of this chapter asked the director general of ASEAN why language had not been discussed, he replied that it would have been like opening Pandora's Box (Edilberto de Jesus, p.c.).

In time, a further five nations joined ASEAN. Brunei joined in 1984, Vietnam in 1995, Laos and Burma (Myanmar) in 1997, and finally Cambodia in 1999. What had been a de facto agreement became de jure with the signing of the ASEAN Charter in 2009, where English was legislated in Article 34 of the Charter as the sole working language of the group.

It is worth pointing out at this stage how linguistically and culturally diverse ASEAN is. For example, Indonesia is home to 700 or so languages and more than 150 languages are spoken in Myanmar and the Philippines. The birth of ELF in ASEAN was therefore attended and potentially shaped by hundreds of languages. When an Indonesian, Filipino, and Burmese are engaged in ELF, many languages may be at work in each speaker's mind.

The legislation of English as the sole working language of ASEAN has had obvious consequences. As Hamied et al. (in press) note, "the official adoption of English as ASEAN's working language has major ramifications on ASEAN member states' educational systems”. These ramifications include the increased presence of English in the curricula (Kirkpatrick, 2010b). For example, Indonesia is the only country of ASEAN that has not made English a compulsory subject in primary school. In the other nine countries, English is introduced, typically from Primary 3. In Brunei, English acts as a medium of instruction from Primary 1. In Singapore, it is the medium of instruction (Kirkpatrick, 2010a). English is also increasingly being used as a medium of instruction in higher education in the region's universities (FentonSmith et al., 2017; Barnard and Hasim, 2018).

Further motivation to learn English for communication within and across ASEAN comes from ASEAN's recent drive to establish an ASEAN identity. The crucial role of English in this enterprise was emphasised by Secretary General of ASEAN Le Luong Minh: 
With the diversity in ASEAN reflected in our diverse histories, races, cultures and belief systems, English is an important and indispensable tool to bring our Community closer together... Used as the working language of ASEAN, English enables us to interact with other ASEAN colleagues in our formal meetings as well as day-today communications ... In order to prepare our students and professionals in response to all these ASEAN integration efforts, among other measures, it is imperative that we provide them with opportunities to improve their mastery of the English language, the language of our competitive global job market, the lingua franca of ASEAN.

(ASEAN, 2013)

English is now firmly entrenched as the Lingua Franca of ASEAN, an area of great linguistic and cultural diversity. As such, it reflects the cultural diversity of its speakers and a decentring away from Anglophone cultures towards more localised and transcultural practices (Baker, this volume). To give just one example, 'English for Islamic Values' is taught in schools attached to mosques in Indonesia (Kirkpatrick, 2015). Its speakers are attuned to the natural diversity and variation of ELF use (see Page, this volume) and use ELF for communication (see Badwan, this volume). Its position as a Lingua Franca has been the result of a top-down policy, with the ASEAN Charter officially nominating English as the sole working language of the group and the Secretary General of ASEAN stressing the importance of English as a tool to create an ASEAN identity and more interaction between ASEAN member states. The use of ELF in ASEAN has, thus, to a certain extent been motivated by official policy from the top. It occurs across ASEAN in a myriad of varied contexts, comprising speakers of different languages in different circumstances, from official ASEAN meetings to ad hoc interactions. We now turn to a completely different context and set of circumstances where ELF has been adopted bottom-up in opposition to official policy, the University of Fribourg.

\section{The Choice of ELF in Academic Settings of One Specific Non-Anglophone University}

As noted previously, when English is used as a Lingua Franca, this can be on an ad hoc basis, for example to address someone (whose language repertoire is) unknown (see Wray and Grace, 2007 on exoteric communication, which is relevant in such ELF contexts) or to perform a task/enact a certain role linked with English spontaneously; but ELF can also be part of an explicit or implicit 'indigenous' (in the sense of Jacoby, 1998; Jacoby and McNamara, 1999) (formal) habit and expectation in which the language choice is anchored in a 
speech event genre for the participants of what might then over time become a community of practice. The way ELF in academic settings at universities outside Anglophone countries can emerge bottom-up to fulfil local needs is a case in point.

The university in question is located in Switzerland, which has four national languages used in their respective territories with rather stable and societally salient language boundaries connecting/separating cantons or areas where French, Italian, or Romansh is spoken, also from the majority-language diglossic German-speaking parts of the country. Most Swiss grow up using either German, French, or Italian, and only the small Romansh-speaking minority become systematically bi- or multi-lingual. School teaching and language exchange within one's own or with neighbouring countries are considered more or less successful ways of learning other national languages. Despite the label 'Latin Switzerland' for the areas in which the Romance languages are spoken and despite the country's Latin designation Confoederatio Helvetica $(\mathrm{CH})$, Switzerland historically had no Lingua Franca.

Regardless of social or educational background, Swiss Germanophones characteristically use prestigious Alemannic varieties of German orally as well as in informal writing. Standard German is a school subject, the language of print and of formal speech. On the German-medium TV news, for example, the news is are read in Standard German but interviews are often conducted in Swiss German. In Francophone cantons, on the other hand, dialect carries very little prestige, and formal literacy in what is perceived as a uniform standard is valued highly. A reluctance to speak an L2 in public or in class can combine with a very assertive use of French in the bilingual canton and town of Fribourg vis-à-vis German speakers, to the extent that French is used in first encounters even by German speakers until they find out that they both are.

Generally, Swiss universities are monolingual institutions whose language depends on the canton in which they are situated. There is one exception, namely Switzerland's Bilingual University, Fribourg/ Freiburg, which has since its foundation in the late nineteenth century been institutionally bilingual in the two cantonal languages, French and German. The complexity of institutional bilingualism and the emergence of English as an additional language will be described briefly. There were periods in the history of the university when the local competition between the two languages was more or less pronounced (or more or less volitional), and co-existence vs. co-operation was a more prominent themes. In fact, the most frequent form of institutional bilingualism, termed "parallel" by Brohy (2005), has in fact been a form of twin monolingualism in which studies can be 
undertaken in either of the two languages to the exclusion of the other. This form requires communicative bridges. A prominent public relations message of the university to this day is its unique position in Europe of offering a complete programme of studies in both French and German. This is not the only form of institutional bilingualism, however. Of Brohy's (2005) tripartite terms, "complementary bilingualism" describes the optional combination of French and German, for example through elements from parallel study programmes. This is intended as an incentive for becoming individually bilingual during one's studies and there are models that lead to certification of the extra effort required in studying through two languages.

The only form of institutional bilingualism that makes an at least passive command of the partner language compulsory without certification is what Brohy (2005) calls "integrated bilingualism”, which in fact, somewhat euphemistically, also included English as used in the science faculty. There was no reduplication of programmes and no segregation of languages, but the natural sciences were offered in French or German, depending on the teacher. Students were allowed to choose in which language to write papers or take exams. 'Scientific English' was a given for research publications, but English was also used orally to accommodate students and staff who did not speak either of the local languages. On the basis of interpersonally compatible language repertoires, Italian has sometimes also played a role, for example, as the language of the lab in research teams headed by an Italian-speaking professor. The use of English was condoned by the 1997 University Law granting faculties the right to specify other languages of instruction but was internally contested as 'unruly/wild trilingualism' and 'proliferation' and seen to undermine bilingualism in French and German. In the course of 2005, there was, however, a flurry of activity in language management, for example a special work group on English led by the representative of the Bilingualism Committee who invited representatives from all faculties to report on the use of English in their faculties. The representative of the science faculty stated that English was in daily use and indispensable to the workings and international success of the science faculty. Towards the end of this year, in the Dies Academicus annual ceremony, it was officially announced by the Rektor/ Recteur in his speech that the Science Master programmes were being taught through English. English was construed in his speech as a force that acts on its own accord, but at the same time, the point was made that English fulfilled functions comparable to Latin in theology, which had long been a 'lingua academica' without interference with bilingualism. 
The situation in the natural sciences that brought about the official acknowledgement in 2005 of the use of English as a primary teaching language in the new master programmes was, however, preceded by and concomitant with the emergence of English in much less visible ecological niches. The 'Beer and Lunch Seminars' in biochemistry and the 'Lunchtime Seminars' in psychology were the first series of disciplinary events in English to emerge during a period of radical change that temporarily culminated in the announcement made at the Dies Academicus referred to earlier. By means of a new genre (Swales, 1990, 2004), English was embedded between the local languages as a Lingua Franca for disciplinary oral presentations and discussions. A comparison of the two lunchtime events as communal disciplinary and public speaking events shows how the use of ELF was developed within the university in response to surrounding language segregation, fostering of global contacts, and disciplinary socialisation needs for oral use of ELF.

Crucially, in both settings, the use of English emerged bottom-up out of people's own vital communal impetus. In both, English was available at least receptively as an international disciplinary language and the multi-lingual agents of change appropriated it for their local purposes and on their own terms. The choice of a local language separates local audiences, producing respective 'others'. A common Lingua Franca thus offers a functional alternative, not only as the only means of communication, but also as an additional one. Instead of code-switching between territorial languages, 'code-sharing' (Schaller-Schwaner, 2010, 2011) in Lingua Franca mode allows for disciplinary cohesion. The use of ELF in the Fribourg University academic settings examined was the most useful common denominator for every individual and for education and research. The extension of ELF in one's multi-lingual repertoire and in one's discipline for local academic speech events therefore served individual and institutional multi-lingualization.

The longitudinal ethnographic contextual analysis of the emergence of ELF in a multi-lingual academic context, mainly as used for lunchtime oral speech events in two different faculties of a bilingual institution with rather different types of institutional bilingualism (segregated or integrative) and hence, motivations to use English, yielded a picture that was rich in detail as well as complex, fluctuating, and dynamic, not least in reconstituting the academic context and to some extent the multi-lingual repertoires of its users. What is essential to bear in mind in all this is these users, however. A language does not emerge of its own accord; it does not itself change an institution or the communicative economy of groups of language users. A language has no agency of its own. Speakers have agency (Ahearn, 2001) and may 
together or individually adapt their communicative repertoires when they are motivated to do so (Gal, 1979). They actualize and co-create the factors that shape their situated English language practice, the ELF code-sharing mode that they adopt for certain purposes, embedded in a highly aware and deliberate way in the local languages but, in the core phases of the speech events, in preference to (code-switching between) the local languages. This is not to deny the influence of structur(ation) but to argue that language users can together try out alternatives and create new experiences that become the new normal (Schaller-Schwaner, 2015, pp. 330-331).

Epistemologically and perhaps also ontologically, these users of English with their awareness, their concerted multi-lingual effort, and their agency make the difference between English as a language in one of the conventional senses (as an abstraction and idealization in the way they are presented elsewhere in this volume) and our take on ELF as a multi-lingual practice and code-sharing mode. Together, these multi-lingual language users shape and make up "the many faces of English" (Schaller-Schwaner, 2017, p. 3) and while it is not entirely clear at this stage if it is just our knowledge that is still blurred or if ELF is indeed, as argued elsewhere, a fuzzy category (SchallerSchwaner, 2017), one thing seems clear: ELF does not exist without its additional language speakers because it is 'their' English. ELF is about a multi-lingual language concept much more than about the presence or absence of L1 users of English, but the presence of an L1 user can trigger foreign language anxiety, unwillingness to communicate, and linguistic insecurity connected to a monolingual language concept and habitus/mindset. In the next section, we describe four factors that combined to motivate the use of ELF in the university.

\section{The Four-Factor Model}

The four factors singled out here appear to be partly overlapping or growing into each other. They will be taken into consideration in turn, starting with the speech event/disciplinary genre factor, moving on to the community of practice factor and the (self)socialization/multilingualization factor before concluding with a brief reappraisal of the foundational ELF concept of the habitat factor for the habitat under consideration.

\subsection{The Speech Event/Disciplinary Genre Factor}

The speech event/genre factor is a crucial one methodologically as well as in terms of the material manifestations of English and the shared (or 
not) purposes of its use. Methodologically, a Swalesian situation first approach (Swales, 2004) was motivated in the Fribourg case by the way in which English first became publicly visible as a local oral practice: in two innovative lunch-time event series for presentations plus discussion, which were unprecedented on university timetables not only because they took place at noon but also because the language of presentations was English.

The speech events in biochemistry, the Beer and Lunch Seminars, were open to everyone but compulsory for all members of all research teams. The doctoral student presenters and peer helpers were in charge and not chaired, unlike occasional invited talks during this weekly time slot by established researchers presenting their own work. All talks and all introductions of invited speakers took place in English. As other languages were sometimes being used interpersonally in low voices in the preparatory phases preceding the chair's or the presenter's taking the floor in English, initiating the phases of the speech event that were exclusively English sometimes sounded effortless and at other times as if presenters had to collect themselves and overcome the competition of other languages for immediate output, but it was always matter of course. The biochemistry unit's decision to use English had also been triggered by a large number of doctoral students from India as well as by the unit's desire to socialize everyone into orally engaging in the disciplinary discourse locally. As illustrated in Schaller-Schwaner $(2009$, p. 257), the unit decided to safeguard disciplinary standards by imposing a regularly updated English-medium textbook for teaching and learning and to familiarize students with cutting-edge publications in the original, English being the "vernacular language" in science. English was also adopted for the speech event 'as a training for students', arguing that keeping to English for the presentation was pedagogically useful as well as easier as it permitted staying in the same language. English was also heard and seen out in the corridors on notice boards and equipment and reported to be used on social occasions that included everyone because it was the only shared language spoken by everyone. While it was thus a responsive choice (in Bell's 2001 sense) to accommodate the Indian students, as elsewhere in the faculty the many other internationals who spoke neither or only one of the local languages, the speech event genre of the Beer and Lunch Seminar was the format that had to be filled with English in a disciplinary role and with a specific academic purpose, locally anchoring English for each individual who had to participate as a member of the audience or as a presenter. Initially, the use of English was perceived as stressful by students, but it became less so with time and experience in the years in which their 
disciplinary persona developed, together with their English in this Lingua Franca context.

The choice of English in the psychology department's Lunchtime Seminar, which was observed in its second and third year of existence, was motivated at that time by the desire to create disciplinary synergies between the only recently united linguistically segregated chairs and their teams who went on to develop a bilingual master's programme in psychology.

The disciplinary speech event anchors the language choice and primes the mind and body for activating English. It is a temporal space and communicative opportunity, a disciplinary and linguistic activity for appropriating and repurposing the journal club (in biochemistry) or brown-bag inspired peer research event (as was the case in psychology) as well as marking the boundary from individual language choice to public speaking language choice, the 'gear shift' to English. This language selection is declarative and effortful but becomes less taxing over time as a genre expectation. While in the years of observation in the psychology event series the language of presentations was announced as English, this is taken as read a decade later, the language of presentations is assumed to be English and therefore not announced.

\subsection{The Community of Practice Factor}

The community of practice (Wenger, 1998) is important for ELF in more than one way, even if ELF encounters may be so transient as to defy a notion of community. In a multi-lingual disciplinary context, in which disciplinary colleagues are struggling to visibly negotiate, navigate, or transcend the local language boundary and realize synergies, the term 'community of practice' is needed to complement the idea of a discourse community (Swales, 1998) that shares a language and conventionalized ways of using it for the specific purpose. The community of practice (henceforth CoP) factor is also visible in the degrees of involvement and the legitimate peripheral participation of members. ELF is not only the two communities' shared resource, however, but is also part of their communal endeavour beyond static language concepts. In psychology the use of ELF was a way of 'getting the German side on board' and 'due to bilingualism' (in whose 'parallel' realization French and German are assumed to index and be intended for its L1 users only), but also an investment in the future of developing (individual repertoires for) a trilingual master's programme. In biochemistry, the international composition of what was at the time a division of the medical department of the science faculty (with its bilingualism 
type of immersing students in alternate languages of instruction) meant that its members had to become familiar with the impact of nine different L1s and had to grow accustomed to each other's Englishes. The biochemists generally held that no one should have to deny his or her origin when using English but 'difficulty understanding' occurred, despite familiarity. The difficulty of converging on English while face-to-face with audience members with whom one shared other, interpersonally established linguistic resources, and inhibiting these as best one could, also required learning to handle this competition for imminent output, mild alertness and resolve, as well as mindfulness of one's best linguistic behaviour in the disciplinary CoP.

\subsection{The (Self)Socialization/Multi-lingualization Factor}

As is becoming clear from the preceding discussion, ELF constellations of dialect-register-genre (James, 2005) can go beyond the typical trigger of no-other-shared-medium scenarios. In fact, linguistic selfdetermination and agency permit users to language in ELF for their purposes beyond the immediate deictic centre, that is the speakers' here-and-now and immediate interlocutors, to psychologically important reference points and 'referees'. Doing English for the communicative autonomy of a future self is a form of taking ownership of English (Widdowson, 1994) in the physical sense of embodiment. Language socialization of self and others into an additional academic language is an 'initiative' language choice in the sense of referee design (Bell, 2001) for important absent others with which one wishes to affiliate and a way of changing the situation, but it is also a way of changing oneself in relation to context and changing one's habitus. Multi-linguals are usually aware that they need to use a language in order to grow it as part of their own practices. The physical experience of speaking English aloud to an audience, intentionally nurturing English in one's repertoire, and literally incorporating it through the mouth as pathway (also vicariously in experiencing close peers doing it) can counteract structuration, realitydefining restrictions. Multi-lingualization is as naturally occurring as other ELF languaging but takes time and tolerance of ambiguity. Small audiences on home turf and informality/sociality signals such as beer or food may ease the process, but the waxing and waning of linguistic resources remains a challenge to participation and self-concept.

\subsection{The Habitat Factor}

The ELF 'habitat factor' that Pölzl and Seidlhofer (2006) established as a foundational aspect both underlines the context sensitivity of ELF 
and helps one examine how far shared ground between interlocutors furthers and hinders international convergence. As explained and illustrated for a specific case in Schaller-Schwaner (2015), the additional language socialization into ELF that the multi-lingual biochemistry CoP provided for doctoral students also provided so much situated familiarity and compatible interlingual resources (as well as shared schemata and terminology) that international intelligibility may have become an issue. ELF as a multi-lingual practice may have a certain contextual Gültigkeitsbereich ('scope'; Auer, 2009, p. 94) and does not automatically transfer as autonomously functional into contexts where other interlingual resources are available. In this sense, the habitat factor is also a limiting factor that needs to be taken into account pedagogically.

\section{Conclusion}

In this chapter, we have considered various aspects of ELF and its origins and stressed its inherent multi-lingual nature and hybridity. Far from ELF being an easily definable stable form of code, we have argued that it is characterised by inherent variation and flexibility. But does this mean that, to reiterate Firth's notion, ELF, as a form, is "inherently, chronically, irremediably variable" (2009, p. 163)? ELF, as a form, can look much like any English. While it is, as Seidlhofer noted, "a 'free language', a linguistic resource that is not contained in, or constrained by traditional (and notoriously tendentious) ideas of what constitutes a 'language'” $(2011$, p. 81), it is situated in realities that make languages and different societal language concepts highly relevant. In positioning themselves explicitly, ELF users position themselves within these discursively available categories while their practices may be in the process of creating new experiences and realities and categories.

Given the spectrum of ontologies of English and the facets of ELF, it may be helpful to consider a continuum of blurred understandings with language as a system at one end and language as social practice at the other. Looking for/at the 'language' English as a reified/artefactualised 'thing' (Blommaert, 2010) towards the system end of the continuum does not deny its inherent variation with ELF towards the social practice end of the continuum, which is still possible to identify as some form of English(ing). It would appear then, that ELF can be more than one thing. What it is not, in our view, is a monolingual construct. ELF needs to be viewed through a multi-lingual lens.

The complexity of ELF is further underscored by the potential of it being, as we argued earlier, a 'responsive' language choice or an 
'initiative' language choice (Bell, 2001). The example of ELF use at the University of Fribourg was bottom up in that it was voluntarily adopted as a choice by its users. In contrast, the use of ELF in ASEAN is the result of a top-down policy decision. We thus underline the importance of context, setting, and the participants themselves, and thus, the need to investigate each case of ELF and where it came from (Dafouz and Smit, 2014). A four-factor model comprising the speech event/disciplinary genre factor, the community of practice factor, the (self)socialization/multi-lingualization factor, and the habitat factor was shown to motivate the choice and use of ELF, but with much variation depending on the particular context.

In summary, ELF needs to be viewed through a multi-lingual lens, understood as a fuzzy category, and one that is contextually determined and open to inherent variation. And it is also English. Named languages may be a discursive reality, an academic paradigm, an argumentative device, an ideological point of identification, and a communicative tool as well as a symbolic claim, perhaps even more in the case of English than in the case of other named languages. English is an emic as well as an etic category and therefore 'plurilithic' and not monolithic.

Schaller-Schwaner (2017) wondered what the etymological stones in the 'plurilithic' concept might actually be. She argued that a metaphor that lends itself to being a conceptual tool worth exploring in further work on English as a Lingua Franca is the image of the beach.

Beaches are inherently dynamic 'landscapes', contact zones and permeable boundary formations shaped by ongoing instability or individual events, they are continually under reconstruction, they have varied and varying forms and the elements and forces they are exposed to and moulded by reinforce or counteract each other in multiple ways. They are also subject to tidal events, global streams and lunar waxing and waning but clearly locally typified and specific to a place.

She suggests that regardless of the specific composition of the beach, it is recognizable as one by anyone who knows the distinction between being out at sea and out of one's depth (with no means of communication) and the relative security of the beach. The beholder's methodological lens is also involved, however:

The granularity of the beach also depends on the granularity of the data transcription and analysis and on the time scale of observation: the length of observation and the point in time/tide and the season. The point is that while traditional language conceptualisations are rather 'land-locked', a more 
dynamic metaphor for languaging which accounts for more dynamic functions and purposes can be useful.

(Schaller-Schwaner, 2017, pp. 327-328)

ELF, we suggest, is like a beach, with stones and pebbles shaping each other through constant contact and subject to external influences, including being buffeted by wind and water. ELF can occur wherever and whenever there are multi-lingual speakers looking to seek out a common language. It is therefore ontologically subjective.

\section{References}

Ahearn, L. M. (2001). Language and agency. Annual Review of Anthropology, 30, 109-137.

ASEAN. (2013, 24 June). Keynote address by H. E. Le Luong Minh, secretarygeneral of ASEAN. Presented at the British Council Conference on Educating the Next Generation of Workforce: ASEAN Perspectives on Innovation, Integration and English. Bangkok.

Asian Corpus of English (ACE). Online. Accessed 25 June 2018 from http:// corpus.ied.edu.hk/ace/

Auer, P. (2009). Context and contextualisation. In J. Verschueren and J Östman, eds. Key Notions for Pragmatics, Vol. 1. Amsterdam and Philadelphia: John Benjamins, 86-101.

Barnard, R. and Hasim, Z., eds. (2018). English Medium of Instruction Programmes: Perspectives from Southeast Asian Universities. London: Routledge.

Bell, A. (2001). Back in style: Reworking audience design. In P. Eckert and J. R. Rickford, eds. Style and Sociolinguistic Variation. Cambridge: Cambridge University Press, 139-169.

Blommaert, J. (2010). The Sociolinguistics of Globalization. Cambridge: Cambridge University Press.

Brohy, C. (2005, 1-3 September). Overt bilingualism, covert multilingualism? Official languages and "other languages" in a bilingual French-German university. Paper presented at the conference on $\mathrm{Bi}$ - and Multilingual Universities: Challenges and Future Prospects, University of Helsinki. Online. Accessed 19 June 2017 from www.palmenia.helsinki.fi/congress/bilingual2005/ abstracts/brohy.pdf

Cogo, A. (2012). ELF and super-diversity: A case study of ELF multilingual practices from a business context. Journal of English as a Lingua Franca, 1 (2), 283-313.

Dafouz, E. and Smit, U. (2014, 11 July). Towards a dynamic conceptual framework for English-Medium education in multilingual university settings. Applied Linguistics, 37(3), 397-415. Online. Accessed from https://doi.org/ 10.1093/applin/amu034

Fenton-Smith, B., Humphreys, P., and Walkinshaw, I., eds. (2017). English Medium Instruction in Higher Education in Asia-Pacific: From Policy to Pedagogy. Dordrecht: Springer. 
Firth, A. (2009). The lingua franca factor. Intercultural Pragmatics, 6(2), $147-170$

Gal, S. (1979). Language Shift. Social Determinants of Linguistic Change in Bilingual Austria. New York: Academic Press.

Grosjean, F. (2001). The bilingual's language modes. In J. L. Nicol, ed., One Mind, Two Languages: Bilingual Language Processing (pp. 1-22). Oxford: Blackwell.

Hall, C. J. (2013). Cognitive contributions to plurilithic views of English and other languages. Applied Linguistics, 34(2), 211-231.

Heller, M. (2007). Bilingualism: A Social Approach. Basingstoke: Palgrave Macmillan.

Hoffman, C. (2000). The spread of English and the growth of multilingualism with English in Europe. In J. Cenoz and U. Jessner, eds. English in Europe: The Acquisition of a Third Language (pp. 1-21). Clevedon: Multilingual Matters.

Hülmbauer, C. (2013). From within and without: The virtual and the plurilingual in ELF. Journal of English as a Lingua Franca, 2(1), 47-73.

Hülmbauer, C. and Seidlhofer, B. (2013). English as a lingua franca in European multilingualism. In A-C. Berthoud, F. Grin, and G. Lüdi, eds. Exploring the Dynamics of Multilingualism. The DYLAN Project (pp. 387-406). Amsterdam: John Benjamins.

Jacoby, S. W. (1998). Science as performance: Socializing scientific discourse through the conference talk rehearsal. Unpublished doctoral dissertation, University of California, Los Angeles.

Jacoby, S. W. and McNamara, T. (1999). Locating competence. English for Specific Purposes, 18(3), 213-241.

James, A. (2005). The challenges of the lingua franca: English in the world and types of variety. In C. Gnutzmann and F. Intemann, eds., The Globalisation of English and the English Language Classroom (pp. 133-144). Tübingen: Gunter Narr.

Joseph, J. E. (2006). Language and Politics. Edinburgh: Edinburgh University Press.

Kirkpatrick, A. (2007). World Englishes: Implications for English Language Teaching and Intercultural Communication. Cambridge: Cambridge University Press.

Kirkpatrick, A. (2010a). English as a Lingua Franca in ASEAN: A Multilingual Model. Hong Kong: Hong Kong University Press.

Kirkpatrick, A. (2010b). English as an Asian lingua franca and the multilingual model of ELT. Language Teaching, 43(3), 1-13.

Kirkpatrick, A. (2015). The future of English in Asia. In M. O'Sullivan, D. Huddart, and C. Lee, eds., The Future of English in Asia (pp. 3-19). Cambridge: Cambridge University Press.

Klimpfinger, T. (2005). The role of speakers' first and other languages in English as a lingua franca talk. Unpublished master's thesis, University of Vienna/ Diplomarbeit Universität Wien.

Klimpfinger, T. (2007). Mind you sometimes you have to mix - The role of codeswitching in English as a lingua franca. Vienna English Working Papers, 16(2), 
36-61. Online. Full text at http://anglistik.univie.ac.at/fileadmin/user_upload/ dep_anglist/weitere_Uploads/Views/Views_0702.pdf).

Klimpfinger, T. (2009). 'She's mixing the two languages together' - Forms and functions of code-switching in English as a lingua franca. In A. Mauranen and E. Ranta, eds., English as a Lingua Franca - Studies and Findings (pp. 348-370). Newcastle-upon-Tyne: Cambridge Scholars Publishing.

Okudaira, A. (1999). A study on international communication in regional organizations: The use of English as the "official" language of the Association of South East Asian Nations (ASEAN). Asian Englishes, 2(1), 91-107.

Ortega, L. (2018). Ontologies of language, second language acquisition and world Englishes. World Englishes, 37, 64-79.

Ostler, N. (2010). The Last Lingua Franca. London: Penguin.

Pölzl, U. and Seidlhofer, B. (2006). In and on their own terms: The "habitat factor" in English as a lingua franca interactions. International Journal of the Sociology of Language, 177, 151-176.

Saraceni, M. (2015). World Englishes: A Critical Analysis. London: Bloomsbury.

Schaller-Schwaner, I. (2009). Under the microscope: English for plurilingual academic purposes. In D. Veronesi and C. Nickenig, eds., Bi-and Multilingual Universities: European Perspectives and Beyond. Bolzano-Bozen: Bozen/Bolzano University Press, 245-264.

Schaller-Schwaner, I. (2010). ELF(A) in the eye of the beholder: Multilingual or monolingual practice. Paper presented at the 11th International CercleS Conference: University Language Centres-Language Policy and Innovation, University of Helsinki, 2-4 September.

Schaller-Schwaner, I. (2011). The eye of the beholder: Is English as a Lingua Franca in academic settings a monolingual or multilingual practice? Language Learning in Higher Education, 1(2), 423-446.

Schaller-Schwaner, I. (2015). The habitat factor in ELF(A) - English as a Lingua Franca (in academic settings) - and English for plurilingual academic purposes. Language Learning in Higher Education, 5(2), 1-23.

Schaller-Schwaner, I. The many faces of English at Switzerland's Bilingual University: English as an academic lingua franca at the institutionally bilingual University of Freiburg/Fribourg - A contextual analysis of its agentive use. Unpublished doctoral thesis, University of Vienna (2017).

Schreier, D. and Hundt, M., eds. (2013). English as a Contact Language. Cambridge: Cambridge University Press.

Scott-Phillips, T. C. (2012, 11 November). The origins of human communication. Signalling signalhood. The Psychologist, 25, 2-3.

Scott-Phillips, T. C. (2017, 8-10 February). Miscommunication, relevance, and the evolution of human communication. Plenary presentation at the COMCOG 2017 Conference Communication and Cognition - Miscommunication: Getting Lost in Language(s). Fribourg: University of Fribourg.

Seidlhofer, B. (2011). Understanding English as a Lingua Franca. Oxford: Oxford University Press.

Smit, U. 2005. Multilingualism and English: The lingua franca concept in language description and language learning pedagogy. In R. Feistaur, I. Cullin, 


\section{Iris Schaller-Schwaner and Andy Kirkpatrick}

C. Cali, and K. Chester, eds., Favorita Papers 04 Mehrsprachigkeit und Kommunikation in der Diplomatie (pp. 66-75). Diplomatische Akademie Wien/ Vienna School of International Studies.

Swales, J. (1990). Genre Analysis: English in Academic and Research Settings. Cambridge: Cambridge University Press.

Swales, J. (1998). Other Floors, Other Voices. A Textography of a Small University Building. Mahwah and London: Lawrence Erlbaum.

Swales, J. (2004). Research Genres: Explorations and Applications. Cambridge: Cambridge University Press.

Wenger, E. (1998). Communities of Practice. Learning, Meaning and Identity. Cambridge: Cambridge University Press.

Widdowson, H. (1994). The ownership of English. TESOL Quarterly, 28(2), 377-388.

Wray, A. and Grace, G. (2007). The consequences of talking to strangers: Evolutionary corollaries of socio-cultural influences on linguistic form, Lingua, 117, 543-578. 